\title{
Representation, Responsive and Indicative
}

\section{Philip Pettit}

Let us assume that one party, A, represents another, B, if and only if A, with B's authorization, purports to speak or act for B. B may authorize A directly, or may authorize the rules under which A is selected to speak or act, and in either event the authorization may consist in a positive endorsement or in a failure to exercise a capacity to disendorse. Building on this assumption about the nature of representation, let us assume in addition that there is some dimension in which the representing party is supposed to be faithful to the represented party so that, depending on the degree of fidelity displayed, the representer may perform better or worse in the representational role: the degree of fidelity provides a criterion for judging the quality of the representation.

These assumptions about the nature and quality of representation put important restrictions on the topic to be addressed here. Thus they mean that A may be statistically - or, more generally, descriptively ${ }^{\mathrm{i}}$ - representative of B without being a representer in our sense. And they mean that A may be an advocate for B without being a representer in that sense. ${ }^{\text {ii }}$ But they still leave a large number of issues open. The relationship envisaged may vary in three more or less familiar ways.

- It may be a relationship between one representer and one representee, or it may assume the form of one-many, many-many or, at the limit, many-one representation. The onemany representation is exemplified by the relationship of a member of parliament to a 
constituency; many-many by the relationship between congress and the people as a whole. iii

- The dimension in which the representer is supposed to be faithful to the representee may be more or less constraining. The representer may just be expected to speak or act on the basis of her own best judgment; or, going to the other extreme, to act according to the preferences or judgments of the representee; or, in between, to act according to the representee's interests or values. The less constrained representer will count as a trustee, the more constrained as a delegate. ${ }^{\text {iv }}$

- However fully authorized, the relationship may or may not give the representee a certain control over how faithful the representer is. Where there is representee-control, the factors that support it may include: a power of selection, a power of deselection, constraints on the process of representative action, constraints on the domain of representative action, and exposure to scrutiny and contestation.

In this essay I want to introduce another respect in which the relationship of representation may vary. Representation may be responsive in character, as I put it, or it may rather be indicative. This distinction has been unduly neglected, because theorists have focused mainly on the responsive variety of representation, and this essay is designed to help correct the balance. $^{\mathrm{v}}$ The discussion is in three sections. In the first, I present the distinction in an abstract form. Then in the second, I describe some ways in which indicative representation has been recognized, side by side with responsive representation, in the tradition of political thought. And, 
finally, in the third section, I ask after the lessons that the recognition of indicative representation has for democratic politics today.

\section{The Basic Distinction}

Imagine that I am invited to take part in a committee - say, a University committee to inquire into how philosophy may be made as attractive to female students as to male. And suppose that I am unable to serve on the committee myself and am given the right to appoint a member in my stead. I accept the offer and think about who I should choose. Believing that the issue is important and trusting in my own values or interests, I want someone who serves in my place to reflect the same attitudes and to speak or act in a way that is faithful to those attitudes.

In this situation I might want to put someone on the committee who will be responsive to my wishes as to how the job should be done: someone who will serve as my deputy. In that case, I will look for a relationship in which I can make those wishes known and exercise some control, say by having the representer consult me. The wishes to which I want to make the representer responsive may be more or less constraining. I may just have a wish that the person should take time and trouble over the committee work, displaying suitable procedural interests or values in the committee's decision-making. ${ }^{\text {vi }}$ Or I might wish that the person should further certain substantive rather than procedural interests or values, supporting decisions of a particular character. Or I might wish, even more constrainingly, that the person implement my instructions on every vote and every decision.

But this is not the only way in which I might seek to be represented on the committee. Instead of seeking to install a responsive deputy, at whatever level of constraint, I might opt for having someone on the committee who shares my general attitudes, whether on procedural or 
substantive matters, and is likely to vote accordingly. I will not expect this person to be responsive to me. I may be happy that she does not know what my attitudes are or even know that I nominated her. I will choose her as a representer because her mentality is indicative of my own. Where she is led in her judgments and decisions, I would be likely to be led, if I were on the committee. Or so at any rate I believe.

This form of representation, like the other variety, would give me a certain control over the committee's reflections and decisions. The representer will not be a responsive deputy, ready to track what I think, whether on procedural or substantive matters. But, if I have chosen well, she will be a reliable indicator of my general attitudes and of where or how I would go on particular issues, were I a member of the committee. I exercise a certain control through her insofar as I chose her for the prospect that she will reflect my attitudes. We might describe her as an indicative proxy rather than a responsive deputy.

The control that I exercise in either of these cases might be increased, of course, with the help of other devices. The control I wield by courtesy of the responsive deputy or the indicative proxy will be increased if I have the power of de-selection as well as selection. And it also likely to be increased if the committee is constrained in a manner that guards against wayward influences. Thus the representative may be forced to make her decisions in a process of salutary interaction with certain other bodies or officials. Or she may be subjected to appropriate limits on the domain of committee action. Or she may be required to defend her decisions under public scrutiny and interrogation. And so on through a number of possibilities.

The essential difference between responsive and indicative representation is easily stated. In responsive representation the fact that I am of a certain mind offers reason for expecting that my deputy will be of the same mind; after all, she will track what I think at the appropriate level. 
In indicative representation things are exactly the other way around. The fact that my proxy is of a certain mind offers reason for expecting that I will be of the same mind; that is what it means for her to serve as an indicator rather than a tracker. From the point of view of my being represented on the committee, having someone there who reflects my mind, it really does not matter whether the representer is a reliable tracker or indicator. This may not even matter from the point of view of my having some control over the committee. Given a power of selection and any of a number of other devices, I can exercise control via the presence of the deputy or the proxy. Either figure can give me a presence on the committee, as we say; either can re-present me.

The distinction between responsive and indicative representation is not my own invention, though it hasn't been explicitly invoked in the political domain and the terms in which I am drawing it are relatively novel. It parallels a distinction in epistemology between two ways in which my beliefs may be reliable: that is, reliable representers of the world they depict. They may be reliable trackers of facts about the world, so that if such and such is the case, then it is likely that I believe such and such. Or they may be reliable indicators of worldly facts, so that if I believe such and such then such and such is likely to be the case. ${ }^{\text {vii }}$

Just as beliefs may relate in either way to the facts they purport to represent epistemically, so representers may relate in either way to the representees that they purport to represent in a political fashion. It may be the case that if a representee has such and such attitudes, at whatever level of grain, then the representer may be expected, in response, to speak and act on those attitudes. Or it may be the case that if the representer speaks and acts on certain attitudes, at whatever level of grain, then the representee may be assumed, given an indicative status, to hold those attitudes. In the first case the attitudes held by the representee are the causal 
source of the attitudes displayed by the representer; in the second, the attitudes displayed by the representer are a non-causal sign of the attitudes held by the representee. The faithful representer in the first scenario will be reliably responsive to the representee; the faithful representer in the second will be reliably indicative of the representee.

\section{The Distinction in Political History}

The staple examples of representation that are given countenance in political theory are almost all cases of responsive representation. Pride of place is given to the representation of a constituency by a member of congress or parliament, or the representation of a people by its legislature or executive, and both are responsive, electorally controlled relationships. Government is to be a government of responsive representers: that is, a government of individuals who are elected to track and respond to their constituencies. And at the same time it is to be a responsively representative government: that is, a government whose electorally disciplined judgments and decisions are supposed to respond to the country as a whole, reflecting public values and opinions.

But where does the idea of indicative representation appear in politics? Where is it recognized in the tradition of political thought? And where does it have application in political institutions?

Three metaphors have dominated the political tradition of thinking about the meaning of representation. Quentin Skinnerviii has recently argued that two of these, associated respectively with the courts and the theater, provide an answer to the responsive idea of representation. As the attorney acts under the explicit or implicit direction of a client, so the idea is that political representers might act as delegated deputies, under the explicit or implicit direction of their 
representees. And as the actor constructively interprets the mind of a character, so the idea is that representers might serve as trustee deputies in interpreting and enacting the mind of representees. But the third metaphor identified by Skinner is drawn from representation in the pictorial arts, and it maps onto indicative representation. As the painting is indicative of how the subject of the painting looks, so on this image should representers be indicative of representees; they should be fitted to serve as proxies, not - or not just - as deputies.

The idea of indicative representation figures early in democratic theory, since it is the sort of representation that is achieved or is likely to be achieved under the lottery system that was favored by the Athenians and that also played an important part in later regimes like those of the Italian city republics. ${ }^{\text {ix }}$ This lottery system might be taken as a version of the technique of random sampling but random sampling put to use in the service of advancing goals espoused by the people as a whole. While it may have been motivated by a desire to have a regular turnover in the representer body, the important thing from our viewpoint is that it would have ensured a degree of proportional and indicative representation.

The indicative idea also appears in the jury system, as that was developed in medieval Europe. ${ }^{\mathrm{x}}$ To be subjected to the judgment of one's peers, whether in determining that there is a legal case to answer, or that one is legally liable, is to be exposed, not to a random arbiter - a chance enemy, perhaps - but to a body that stands in for the community as a whole. The idea is that the jurors should represent a cross-section of the community or at least of the fully enfranchised members: in medieval Europe, the mainstream, propertied males. ${ }^{\mathrm{xi}}$

The indicative image of representation is particularly evident in those parliamentarian writers in England of the mid-seventeenth century who look for a "speaking likeness" of the people in those who rule them, “describing Parliament as a "representation” - a picture or 
portrait - of the body of the people."xii And, perhaps as a result of that precedent, it became an established element in the thinking of those associated with the American war of independence and the French revolution.

Thus Melanchton Smith could write in 1788, in opposing the American constitution: "The idea that naturally suggests itself to our minds, when we speak of representatives is, that they resemble those they represent; they should be a true picture of the people.”xiii Again, the idea was powerfully endorsed in a speech given by Mirabeau to the French Constituent Assembly in January 1789, though he used the image of a map rather than a picture to get it across. According to this version of the model, "a representative body is to the nation what a chart is for the physical configuration of its soil: in all its parts, and as a whole, the representative body should at all times present a reduced picture of the people - their opinions, aspirations, and wishes, and that presentation should bear the relative proportion to the original precisely as a map brings before us mountains and dales, rivers and lakes, forests and plains, cities and towns." xiv

With the growth of electoral machinery, the indicative idea was naturally applied to elections for the legislature, providing support for making the electoral system more and more proportional. ${ }^{\mathrm{xv}}$ Is it also behind the practice of organizing the legislature around geographically dispersed districts? It is hard to believe that it did not play some role in justifying that practice but the evidence, according to Andrew Rehfield, ${ }^{\text {xvi }}$ is against this hypothesis. Still, districting does induce a similarity in one dimension - nowadays a fairly unimportant one - between the population as a whole and the legislature that represents it.

The indicative idea survives in the continuing enthusiasm for proportional representation and has been given new life in campaigns for supplementing electoral representation with novel, 
statistically representative bodies. It is there in the general policy of organizing citizens' juries that would review various policy issues. ${ }^{\text {xvii }}$ And it is present in the notion of the deliberative opinion poll that is chosen as a random sample and then canvassed for its view on one or another issue at two separate times: first, before members of the sample make contact with one another, and, second, after they come together to receive background information, to hear different points of view and to debate the right line to take on the issue under consideration. ${ }^{\text {xviii }}$

A particularly striking example of this general device appears in the Citizens’ Assembly that was recently established in the Canadian province of British Columbia. ${ }^{\text {xix }}$ A more or less representative sample of 160 citizens was assembled and given the task, over much of 2004, of reviewing the existing electoral system in the light of various hearings and discussions, and making a recommendation on whether or not it should be amended. The group recommended a change that then went to referendum and won more than $50 \%$ support but fell short of the quota required to trigger a change. ${ }^{\mathrm{xx}}$

\section{The Lessons for Contemporary Politics}

As this review suggests, the main form of recognition that has been traditionally given to the distinction between the two forms of representation - and, in particular, to the role of indicative representation - is associated with the drive for proportionality in elected legislative bodies. John Stuart Mill, in particular, made this a centerpiece of his democratic philosophy and it continues to be a cause that is pushed in political theory. ${ }^{\text {xxi }}$

A first lesson of the discussion so far, however, suggests that this one area where there has been some emphasis on indicative representation is ill selected. Given the different bases of responsive and indicative representation, it is not at all clear that the two modes can be usefully 
mixed. And making an electoral, purportedly responsive body into a body that is also indicative of the population represented may prove to be a hopeless task.

In order to serve as an indicatively representative body, a legislature would have to meet two conditions. First, it would have to be statistically representative, embodying a range of attitudes that correspond distributively to those in the population at large. And second, its members would have to be disposed to act on those attitudes, reaching conclusions that we might expect the population as a whole to reach, could it operate in a single deliberative assembly. The problem with making an elected legislature proportional is that while proportionality would make for fulfillment of the first condition, the fact that the body is elected is likely to militate against its fulfillment of the second.

The reason for this possible failure is easy to see. The members of a body like the British Columbia Citizens’ Assembly are likely to vote as their independently determined attitudes lead them, in light of their deliberation, to do so. They have no ulterior motives that would warp this pattern and it is for that very reason that we can have confidence in the body; we may think that as they are led to vote so would the population as a whole have voted could they have assembled and deliberated appropriately. But this consideration is not going to apply with an elected body, at least if re-election is a possibility. For the members of such a body are likely to be moved, not just by the independently held attitudes that reflect the spread of attitudes in the community, but also by the desire to be re-elected - or for their party to be re-elected - and, more generally, by the desire to make a good impression on their supporters and on those who provide them with financial and other backing.

But while proportionality may not help to make an elected body indicatively representative, is it likely to help in other ways: say, in establishing a body with which people 
generally can identify as with a microcosm of their community? It may help in this way, but there is a countervailing consideration to put on the scales as well. This is that as an elected body becomes more and more proportional, there is less and less likelihood that any one party or close alliance of parties, and so any one package of policies, will prevail. But that means in turn that with every policy to be implemented there is likely to be a struggle between small groups, as the government seeks to buy off enough support to get a majority. The government in such a situation will certainly be a government of representatives - in Burke’s image, it may operate like a “congress of ambassadors” - but it may not be a very representative government. It may put forward a patchwork of policies, each customized to get a suitable majority, that represents an outcome of crude interest-group bargaining. The package may not answer to the values of the community, not having to be defended, as a whole, in terms that all treat as relevant to collective decision-making. ${ }^{\text {xii }}$

The first, tentative lesson of our discussion, then, is negative: making legislatures more and more proportional will not make them indicative and may have bad representative effects overall. But there are three other lessons that I am inclined to draw and they are more positive in character.

The first of these lessons is that there is very good reason why contemporary democracies might make more use of devices like the British Columbia Citizens’ Assembly. Once we see that indicative representation is a bona fide mode of representation, subject to democratic control, the use of this sort of body comes to be very attractive. For clearly a government might make use of such bodies in a variety of contexts, taking their decisions, perhaps subject to approval in a referendum, as guides to legislation or even determinants of legislation. There are many very general issues that government faces where this mode of decision-making would be usefully 
informed and representative and would carry unassailable democratic credentials. Any objections that might be made to the use of such a device ought to be silenced in light of an appreciation of the possibility of indicative representation.

The second of the positive lessons I am inclined to draw is less radical but, paradoxically, may be more controversial. It is that once we have the notion of indicative representation on hand, we can see familiar, unelected bodies and authorities as indicatively representative and so as possessed in their own right of democratic credentials.

Consider the electoral commission or commissioner who is charged with establishing the boundaries of electoral districts. Or the auditor general who is given the job of reviewing the government's books. Or the bureau of statistics that has the task of making impartially derived statistics public. Or the ombudsman who provides an office for hearing and adjudicating various complaints about government administration. Or the central bank or federal reserve whose role it is to determine interest rates. Or indeed the judges whose brief is to interpret and apply the law impartially.

In standard ways of thinking, such figures - such statutory officers, to use a Westminster term - are authorized because of their mode of appointment by responsive, elected representatives. But authorized to do what? This is a problem for standard theory. The salient answer, that they are authorized like regular bureaucrats to act as agents of the elected representatives, does not fit with the independence they are given. But an alternative answer becomes available once we have the idea of indicative representation on hand. This is that they are authorized to act, in suitable domains, as indicative representers of the people.

In the areas where statutory authorities and bodies operate, it is fairly clear what the interest of the public is, by almost any criterion of public interest. And in these areas, the 
appointment of people with a professional investment in serving that interest - and, ideally, with a virtuous disposition to further it - promises to serve the public well. Their inclinations ought to conform in general to the requirements of the public interest, at least if they have the virtues of good statisticians, good auditors, good judges, and so on. And so in the relevant domain of public interest, they ought to be reliable, indicative representers of the people at large.

It may be said that giving representative power to statutory figures is a rash move, as it does not allow the people democratic control over their operation. But this is manifestly not so, for the virtue that would make them reliably indicative of the public interest can be strongly reinforced, even elicited, in a suitable institutional context. The individuals and bodies in question can be exposed to parliamentary, executive and popular contestation, constrained by rules for how and where they operate, dismissed for improper performance and subjected to a discipline of re-appointment. And in any case, they can be exposed to reputational constraints that give them a powerful personal interest in avoiding ignominy and winning esteem among their colleagues, and among the public in general. ${ }^{\text {xxiii }}$

Can statutory authorities be seen, however, in a distinct, responsive light? Can they be depicted as representers who are responsive to the wishes of the people that they should conduct themselves in office according to a certain brief? This is not, in general, plausible, at least not with the sorts of statutory officers we are inclined to admire. Were they responsive representers of that stripe, then we should expect them to behave in this or that manner, depending on how the wishes of the people varied. But this is precisely what we would not expect of any statutory individual or body that we thought worthy of admiration.

The third positive lesson that I draw from this discussion is that it is not just proportional bodies or statutory appointees who can count as unelected representers of the people. With the 
category of indicative representation in hand, we also have to recognize the indicatively representative role of the whistle-blowers and complainants who expose abuses in public life or the private citizens who challenge and expose the unconstitutional character of certain laws. These are the "private attorneys general," ${ }^{\text {xxiv }}$ so called, who serve the public well by challenging certain laws before the courts, or indeed administrative policies before appropriate tribunals or officials. The fact that the public or people give such complainants a license to use the courts and tribunals as they do - and the fact that they often provide protection against various forms of retaliation - means that these figures are authorized to act in their characteristic manner. When they act, they do so under conditions that are laid down in laws that they public accepts and so they act under a suitable degree of public control. Did their action cease to serve the public interest, perhaps creating an intolerable nuisance in the working of the system, then presumably those laws would be changed.

Private attorneys general serve the public well in the aggregate, acting on interests that converge with a manifest public interest. It may not be in the public interest that the law or policy challenged by such a figure is set aside or modified but it will certainly be in the public interest that there is the sort of interrogation of law and policy that private attorneys general trigger. Indeed this is routinely recognized in the way in which complainants often claim to be acting in the name of the people. Their authorization by the public means that like formally appointed officials, they can be seen as representers who are allowed to play their particular part, because of the indicative relationship between their dispositions and the presumptive dispositions of the people as a whole.

These positive lessons should help to underscore the importance of recognizing that public representation may be indicative as well as responsive. Indicative representers may not be 
elected but they are nonetheless important for that. Their democratic legitimacy is ensured by the fact that they are still subject to a significant degree of public control. And their democratic utility - indeed their democratic indispensability - is manifested by the unique way in which they can serve the public. The citizen assembly can provide a fine indicator of how the people would go on a certain issue, were they well informed; certainly it may provide a better indicator in many domains than the consensus among elected representatives. Statutory officers can provide a reliable determination of how the public interest is best served in areas where the interests of elected representatives can induce a self-serving instability. And private attorneys general can hold all other representatives, elected and unelected, to standards and interests that have a constitutional or other hold in the community. Democracy is too important to be left to elected politicians alone. ${ }^{\mathrm{xxv}}$ We need indicative as well as responsive representation in public life. ${ }^{\text {xxvi }}$

\section{NOTES}

\footnotetext{
${ }^{\mathrm{i}}$ Hanna Pitkin, The Concept of Representation (Berkeley: University of California Press, 1972).

ii Nadia Urbinati, "Representation as Advocacy: A Study of Democratic Deliberation," Political Theory 28 (2000).

iii Philip Pettit, "Three Varieties of Public Representation," Representation and Popular Rule, ed. Ian Shapiro, Susan Stokes, and E.J.Wood (Cambridge: Cambridge University Press, 2008).

iv Pitkin, The Concept of Representation.

${ }^{v}$ I drafted this paper, and published another on similar lines (see Pettit, "Three Varieties of Public Representation") in ignorance of a wonderfully comprehensive article by Jane Mansbridge ("A "Selection Model" Of Political Representation," Journal of Political Philosophy 17 (2009)) that documents the history of a closely related distinction between a sanctions and a selection model of representation and establishes a range of points bearing on how the selection model may be developed. That article is broadly congenial to the viewpoint I defend here, though it is more sanguine about the possibility of combining responsive and indicative representation.

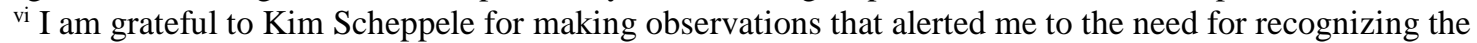
possibility that procedural considerations might play the same role in responsive representation as considerations of a more substantive kind.

vii Ernest Sosa, A Virtue Epistemology (Oxford: Oxford University Press, 2007).

viii Quentin Skinner, "Hobbes on Representation," European Journal of Philosophy 13 (2005).

ix Mogens Herman Hansen, The Athenian Democracy in the Age of Demosthenes (Oxford: Blackwell, 1991); Daniel Waley, The Italian City-Republics, 3rd Ed (London: Longman, 1988).

x Jeffrey Abramson, We, the Jury: The Jury System and the Ideal of Democracy (New York: Basic Books, 1994).
} 
${ }^{x i}$ It is significant that a supporter of the anti-federalist cause in 1787 could complain that in the enlarged United States there would not be a representative body in legislature or jury 'which possesses the same interests, feelings, opinions, and views the people themselves would were they all assembled' Ralph Ketcham, ed., The AntiFederalist Papers (New York: Signet Classic, 2003), 265.

xii Quinten Skinner, "Hobbes on Representation," European Journal of Philosophy 13 (2005): 155-184.

xiii Ketcham, ed., The Anti-Federalist Papers, 342

xiv Hannah F. Pitkin, ed., Representation (New York: Atherton Press, 1969), 77.

xv John Stuart Mill, Considerations on Representative Government (London: Everyman Books, 1964).

xvi Andrew Rehfield, The Concept of Constituency: Poltical Representation, Democratic Legitimacy, and Institutional Design (Cambridge: Cambridge University Press, 2005).

xvii J. Stewart, E. Kendall, and A Coote, Citizens' Juries (London: Institute of Public Policy Researcg, 1994).

xviii James S. Fishkin, The Voice of the People: Public Opinion and Democracy (New Haven, Conn.: Yale University Press, 1997).

xix Mark E Warren and Hillary Pearse, eds., Designing Deliberative Democracy (Cambridge: Cambridge University Press, 2008).

${ }^{x x}$ Since everything is a perfect indicator of itself, a limit case of indicative representation is the participatory democracy where the whole population is present to vote, not just a sample. Far from being cast as the contrast point for indicative representation, the compulsory, participatory arrangement can be seen as a special case. The case is so special, however, and so infeasible, that I ignore it in this discussion.

xxi Thomas Christiano, The Rule of the Many: Fundamental Issues in Democratic Theory (Boulder, Colorado: Westview Press, 1996).

xxii See the appendix, written together with Rory Pettit, to Pettit, "Three Varieties of Public Representation." The argument there is that the presidential, Washington system can have the same effect of sacrificing representative government to government by representatives.

xxiii Geoffrey Brennan and Philip Pettit, The Economy of Esteem: An Essay on Civil and Political Society

(Oxford: Oxford University Press, 2004). 61 (1998).

xxiv Jeremy A. Rabkin, "The Secret Life of the Private Attorney General," Law and Contemporary Problems

xxv Philip Pettit, "Depoliticizing Democracy," Ratio Juris 17 (2004).

xxvi I was aided greatly in developing this paper by discussion at a workshop on representation in Princeton, December 2008, organized by Nadia Urbinati, Mark Warren and Steve Macedo. I am particularly grateful to Annie Stilz, who was my commentator, and to Jenny Mansbridge and Mark Warren for later exchanges.

\section{Philip Petit}

